\title{
2-Octadecynoic acid as a dual life stage inhibitor of Plasmodium infections and plasmodial FAS-II enzymes
}

\author{
Néstor M. Carballeira ${ }^{\mathrm{a}, *}$, Angela Gono Bwalya ${ }^{\mathrm{b}}$, Maurice Ayamba Itoe ${ }^{\mathrm{c}}$, Adriano D. Andricopulo ${ }^{\mathrm{d}}$, \\ María Lorena Cordero-Maldonado ${ }^{e}$, Marcel Kaiser ${ }^{\mathrm{f}, \mathrm{g}}$, Maria M. Mota ${ }^{\mathrm{c}}$, Alexander D. Crawford ${ }^{\mathrm{e}}$, \\ Rafael V. C. Guido ${ }^{\mathrm{d}}$, Deniz Tasdemir ${ }^{\mathrm{b}, \mathrm{h}, *}$ \\ a Department of Chemistry, University of Puerto Rico, PO Box 23346, San Juan 00931-3346, Puerto Rico \\ ${ }^{\mathrm{b}}$ Department of Biological and Pharmaceutical Chemistry, University of London, School of Pharmacy, London WC1N 1AX, UK \\ ${ }^{\mathrm{c}}$ Instituto de Medicina Molecular, Universidade de Lisboa, Lisbon 1649-028, Portugal \\ ${ }^{\mathrm{d}}$ Laboratório de Química Medicinal e Computacional, Centro de Pesquisa e Inovação em Biodiversidade e Fármacos, Instituto de Física de São Carlos, \\ Universidade de São Paulo, São Carlos, SP 13563-120, Brazil \\ e Chemical Biology Group, Luxembourg Centre for Systems Biomedicine, University of Luxembourg, L-4362 Esch-sur-Alzette, Luxembourg \\ ${ }^{\mathrm{f}}$ Department of Medical Parasitology and Infection Biology, Swiss Tropical and Public Health Institute, CH-4002 Basel, Switzerland \\ ${ }^{\mathrm{g}}$ University of Basel, Petersplatz 1, CH-4003 Basel, Switzerland \\ ${ }^{\mathrm{h}}$ School of Chemistry, National University of Ireland, Galway, Ireland
}

\section{A R T I C L E I N F O}

Article history:

Received 7 July 2014

Revised 15 July 2014

Accepted 17 July 2014

Available online 24 July 2014

\section{Keywords:}

Acetylenic fatty acids

Blood stage

Liver stage

Malaria

2-Octadecynoic acid

Plasmodium

Type II fatty acid synthase

\begin{abstract}
A B S T R A C T
The malaria parasite Plasmodium goes through two life stages in the human host, a non-symptomatic liver stage (LS) followed by a blood stage with all clinical manifestation of the disease. In this study, we investigated a series of 2-alkynoic fatty acids (2-AFAs) with chain lengths between 14 and 18 carbon atoms for dual in vitro activity against both life stages. 2-Octadecynoic acid (2-ODA) was identified as the best inhibitor of Plasmodium berghei parasites with ten times higher potency $\left(\mathrm{IC}_{50}=0.34 \mu \mathrm{g} / \mathrm{ml}\right)$ than the control drug. In target determination studies, the same compound inhibited three Plasmodium falciparum FAS-II (PfFAS-II) elongation enzymes PfFabI, PfFabZ, and PfFabG with the lowest IC 50 values $(0.28-0.80 \mu \mathrm{g} /$ $\mathrm{ml}$, respectively). Molecular modeling studies provided insights into the molecular aspects underlying the inhibitory activity of this series of 2-AFAs and a likely explanation for the considerably different inhibition potentials. Blood stages of $P$. falciparum followed a similar trend where 2-ODA emerged as the most active compound, with 20 times less potency. The general toxicity and hepatotoxicity of 2-AFAs were evaluated by in vitro and in vivo methods in mammalian cell lines and zebrafish models, respectively. This study identifies 2-ODA as the most promising antiparasitic 2-AFA, particularly towards $P$. berghei parasites.
\end{abstract}

c) 2014 Elsevier Ltd. All rights reserved.
With more than one third of the planet's population at risk of infection, malaria remains the most devastating parasitic disease. Past and current research for antimalarial drug discovery has largely focused on easily cultivable blood stage (BS) parasites for the treatment of the disease. The major problem in this area is the emergence of drug resistance. Even against the artemisinins and their combination therapies there are already reports of signs of resistance. ${ }^{1,2}$ Liver stage, the first, clinically silent stage preceding the symptomatic BS in humans, is recently gaining research interest, due to low parasite load, hence a lower risk of resistance development. Most importantly, elimination of liver stage (LS)

\footnotetext{
* Corresponding authors.

E-mail addresses: nestor.carballeira1@upr.edu (N.M. Carballeira),deniz.tasdemir@ nuigalway.ie (D. Tasdemir).
}

parasites provides causal malaria prophylaxis through blockage of the initiation of the BS. Sadly, primaquine, the only FDA approved drug with LS activity is associated with many drawbacks and limitations. Therefore, new approaches might be necessary for both prevention and treatment of malaria. This could include the identification of new drug candidates with selectivity against one life stage, as well as dual inhibition of both liver and blood forms.

Among the vast number of acetylenic fatty acids known to date, the 2-alkynoic fatty acids (2-AFAs) are among the most interesting for the diversity of biological activities that they display coupled to the challenging mechanisms of action underlying their toxicity towards a wide range of pathogenic cells and organisms. In this context, 2-hexadecynoic acid (2-HDA) is among the best-studied 2AFAs. 2-HDA displays in vitro antimycobacterial, ${ }^{3}$ antileishmanial, ${ }^{4}$ antiplasmodial, ${ }^{5}$ antibacterial, ${ }^{6}$ antifungal ${ }^{7}$ and cytotoxic activity. ${ }^{8}$ 
Different mechanisms proposed to date responsible for the bioactivity of the 2-AFAs include dual inhibition of fatty acid biosynthesis by two 2-HDA metabolites (3-oxohexadecanoic acid and 3-hexadecynoic acid) that block key metabolic enzymes responsible for fatty acid biosynthesis and degradation, ${ }^{3}$ inhibition of important protozoal enzymes such as topoisomerases IB and type II fatty acid synthase (FAS II) enzymes, ${ }^{4,5}$ inhibition of fatty acid elongation and acylation, in particular triglyceride synthesis in cancer cells, ${ }^{8}$ as well as necrosis. ${ }^{9}$

Previous studies on 2-HDA and other analogs have shown that the alkyl chain length is the most important determinant for the biological activity of the 2-AFAs. The important work by Morbidoni et al. (2006) has identified a relationship between fatty acid chain length and antimycobacterial activity against Mycobacterium smegmatis. $^{3}$ In the latter work Morbidoni established that the antimycobacterial activity of the 2-AFAs decreased in the order $\mathrm{C}_{18}>\mathrm{C}_{16}>\mathrm{C}_{19}>\mathrm{C}_{14}>\mathrm{C}_{20} \approx \mathrm{C}_{22} \approx \mathrm{C}_{12}$. This trend has remained constant against other biological systems as well, in particular with respect to their antiprotozoal activities. ${ }^{4}$ We recently reported on the slightly better antileishmanial activity of 2-octadecynoic acid (2-ODA, $\left.\mathrm{C}_{18}\right)$ when compared to 2-HDA $\left(\mathrm{C}_{16}\right)$ against Leishmania donovani ( $\mathrm{EC}_{50}$ value of $11 \mu \mathrm{M}$ vs $17.8 \mu \mathrm{M}$, respectively). The same trend also translates into target enzyme inhibition since in the latter study 2-ODA turned out to be a better inhibitor of the Leishmania topoisomerase IB enzyme as compared to either 2-HDA or 2-tetradecynoic acid (2-TDA, $\mathrm{C}_{14}$ ) with $\mathrm{EC}_{50}$ values of $5 \mu \mathrm{M}$ vs 28 and $68 \mu \mathrm{M}$, respectively. ${ }^{4} \mathrm{~A}$ plausible explanation for this tendency has not been proposed yet. Sanabria-Ríos et al. (2014) determined the critical micelle concentration (CMC) of both 2-AFAs and found that the CMC of 2-HDA (CMC $>90 \mu \mathrm{g} / \mathrm{ml})$ is higher than the CMC of 2-ODA $(\mathrm{CMC}=50 \mu \mathrm{g} / \mathrm{ml}) .{ }^{6}$ However, whether this translates into their biological activities remains to be investigated.

In a recent study, we reported in vitro antiprotozoal activity of 2-HDA towards BS of Plasmodium falciparum ( IC $_{50}=10.4 \mu \mathrm{g} / \mathrm{ml}$ ) and LS forms of Plasmodium yoelii $\left(\mathrm{IC}_{50}=15.3 \mu \mathrm{g} / \mathrm{ml}\right) .{ }^{5}$ Moreover, we were able to show that 2-HDA was a potent inhibitor of the $P$. falciparum type II fatty acid synthase (PfFAS-II), a key system for de novo production of fatty acids in the late LS development of the parasite. ${ }^{5} 2$-HDA blocks the activity of three crucial PfFASII enzymes responsible for enoyl reduction (PfFabI), $\beta$-hydroxyacyl dehydration (PfFabZ), and $\beta$-ketoacyl reduction (PfFabG) with $\mathrm{IC}_{50}$ values ranging between 0.38 and $3.50 \mu \mathrm{g} / \mathrm{ml}^{5}$ Based on these preliminary results, we have extended our work to the synthesis and antimalarial activity assessment of 2-ODA and 2-TDA against both BS (P. falciparum K1) and LS (Plasmodium berghei) parasites. The potential activity of these 2-AFAs against the same PfFAS-II enzymes was also studied by in vitro enzyme inhibition assays and docking studies. Finally, in vitro and in vivo toxic and hepatotoxic potential of 2-ODA, 2-TDA, 2-HDA, as well as palmitic acid (PA) was investigated on cell lines and zebrafish larvae to allow the identification of the most promising acetylenic fatty acid of the series.

The synthesis of 2-TDA, 2-HDA, and 2-ODA was previously reported by us and others. ${ }^{4,10}$ These compounds are synthesized from the reaction of the corresponding 1-alkyne with $n$-BuLi in $\mathrm{THF}$ at $-70{ }^{\circ} \mathrm{C}$ followed by quenching with $\mathrm{CO}_{2}$ followed by protonation with $\mathrm{NH}_{4} \mathrm{Cl}$. The purity of all the final AFAs was $>97 \%$, as determined by capillary GC-MS and ${ }^{13} \mathrm{C}$ NMR.

We first studied the growth inhibitory effects of 2-ODA and 2-TDA against $P$. falciparum $\mathrm{K} 1$ and $P$. berghei parasites, and compared these to those of 2-HDA and PA. To achieve this, hepatoma Huh7 cells were infected with rodent malaria parasite, luciferaseexpressing $P$. berghei sporozoites and treated with compounds for $48 \mathrm{~h}$, as described previously. ${ }^{11}$ Treatment with 2-ODA and 2-TDA greatly impaired infection (Fig. 1) with no apparent effects on cell viability of host human hepatic cell (Huh7) as determined
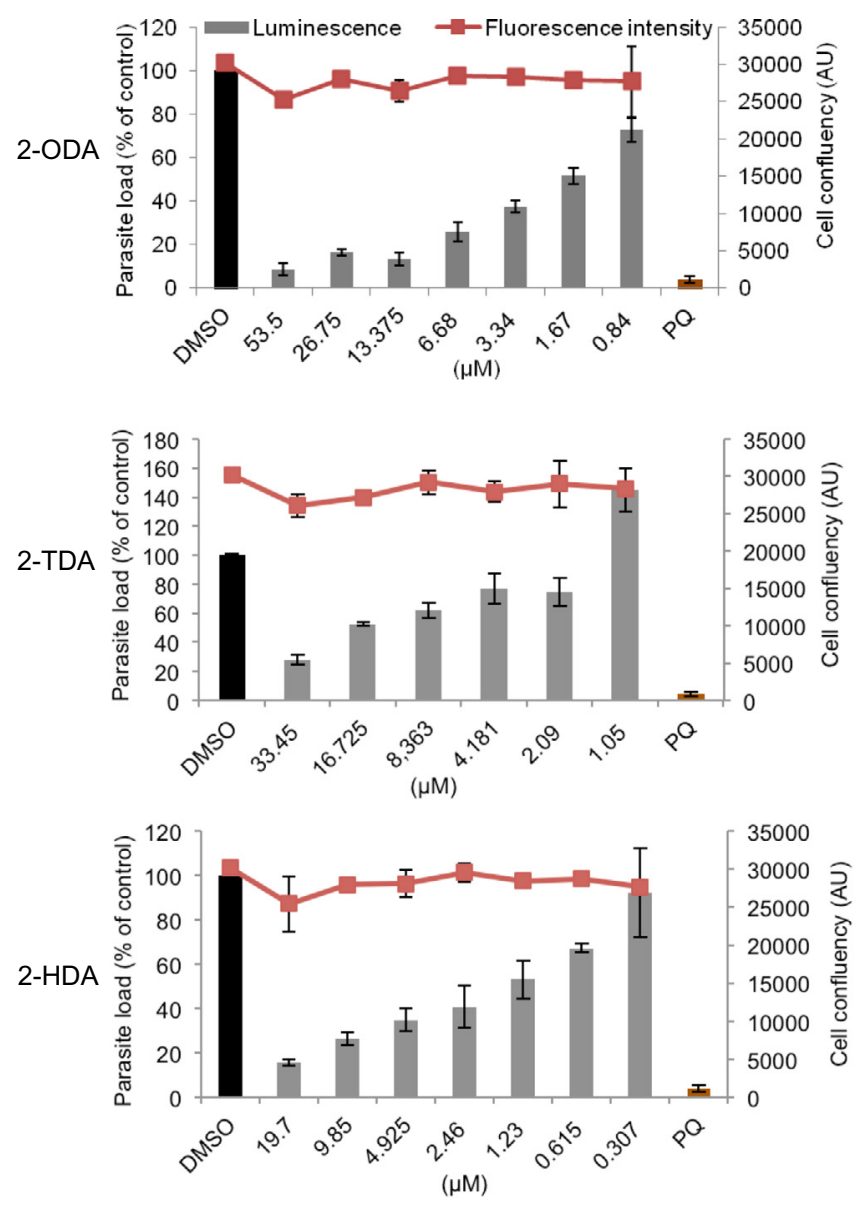

Figure 1. Impairment of $P$. berghei infection in human hepatoma cells, Huh7, by 2 AFAs. Human hepatoma cells were infected with luciferase-expressing $P$. berghe sporozoites and treated at 2hpi with 2-fold dilutions of test compounds; 2-ODA, 2TDA, 2-HDA or DMSO (vehicle), or $15 \mu \mathrm{M}$ primaquine (internal control). Infection (expressed as percentage of control) was analyzed at $48 \mathrm{hpi}$. Red lines indicate cell confluency at the time of analysis. AU: arbitrary units.

by fluorescence intensity measurements after incubation with the active plasma membrane labeling dye Alamar Blue (red line, Fig. 1). Confocal imaging of parasites immunostained with antiPbHsp70 ( $P$. berghei heat shock protein 70, green) antibody reveals that parasites were greatly impaired in development as shown by representative images (Fig. 2). As shown in Table 1, 2-ODA was the most potent $P$. berghei active compound with an $\mathrm{IC}_{50}$ value $(0.34 \mu \mathrm{g} / \mathrm{ml})$ that was ten times lower than the control compound, primaquine. This potency is even superior to that of 2-HDA $\left(\mathrm{IC}_{50}=0.48 \mu \mathrm{g} / \mathrm{ml}\right.$ ) on $P$. berghei (Table 1$)$. Interestingly, we previously determined a lower anti-LS activity of 2-HDA against another rodent model, $P$. yoelii, with $\mathrm{IC}_{50}$ values of $15.3 \mu \mathrm{g} / \mathrm{ml}$ (assessed by flow cytometry) and $4.88 \mu \mathrm{g} / \mathrm{ml}$ (assessed by immunofluorescence activity). ${ }^{5}$ The potency of 2 -TDA on the hepatic stage $P$. berghei parasites was much poorer $\left(\mathrm{IC}_{50} 2.87 \mu \mathrm{g} / \mathrm{ml}\right.$ ), whereas PA was devoid of any LS activity at the highest test concentration $(25 \mu \mathrm{g} / \mathrm{ml})$.

In our effort to find a plausible mechanism of action of 2-ODA towards the Plasmodium parasites, as well as to compare these results to those previously reported by us for 2-HDA, we assessed the inhibitory potency of the three 2-AFAs towards PfFAS-II enzymes, namely PfFabI, PfFabZ, and PfFabG. All of these enzymes were recombinantly prepared and evaluated following a previously published procedure. ${ }^{12}$ Again 2-ODA appeared as the most effective inhibitor of the key elongation enzymes in the PfFAS-II pathway of Plasmodium, following the order PfFabI $\approx$ PfFabZ $>$ PfFabG (Table 1). Notably, the enzyme inhibitory potential of 2-ODA 


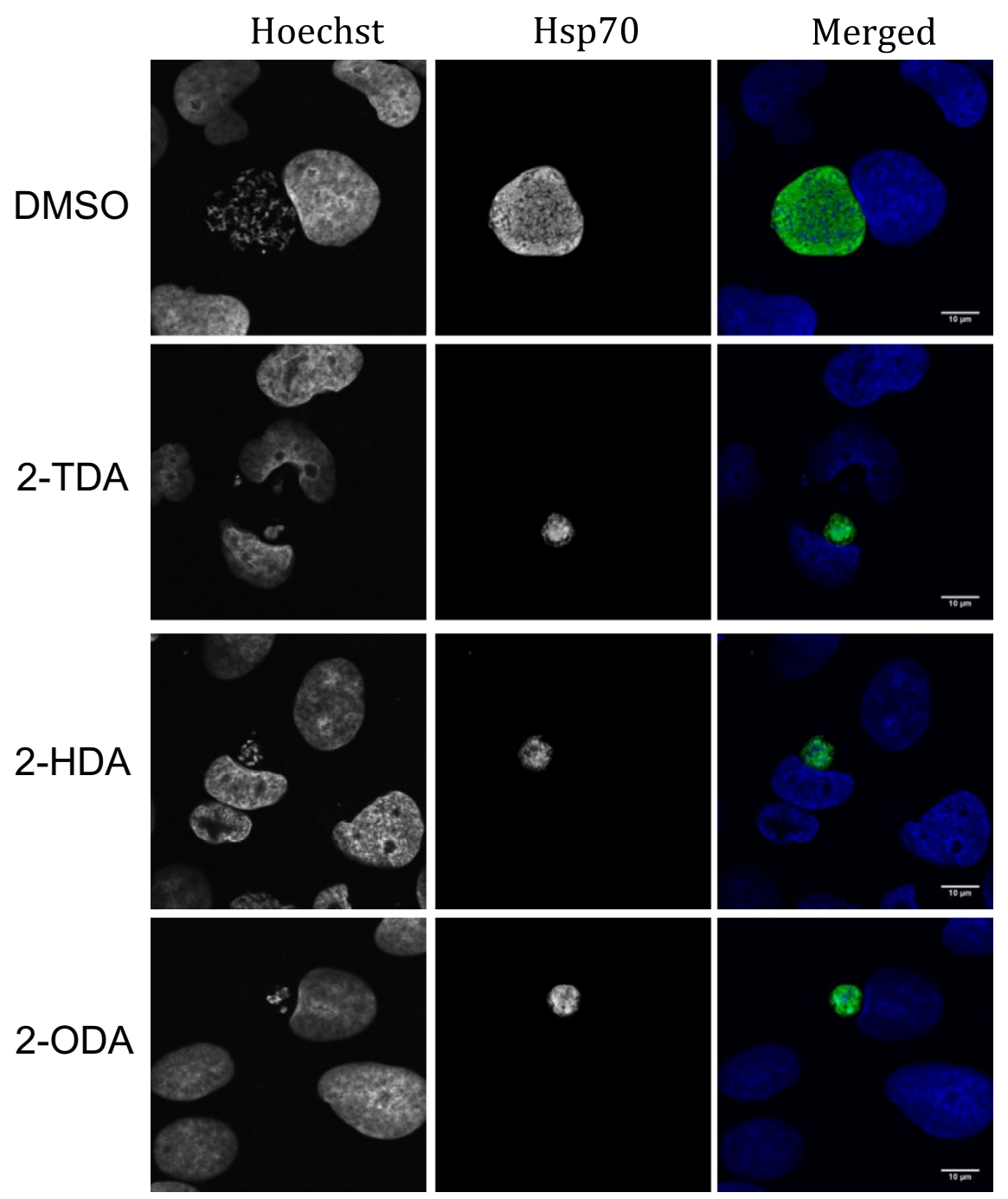

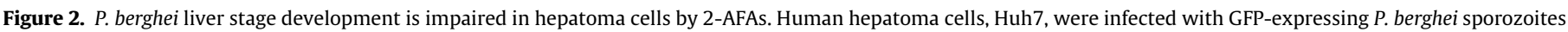

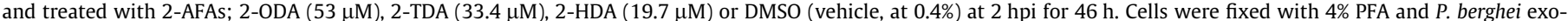

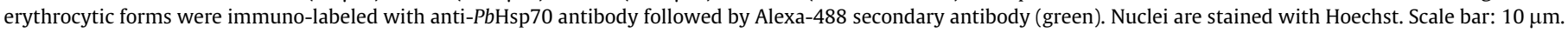

(IC 50 's 0.28 to $0.8 \mu \mathrm{g} / \mathrm{ml}$ ) was identical or comparable to its P. berghei antiparasitic activity ( $\mathrm{IC}_{50} 0.34 \mu \mathrm{g} / \mathrm{ml}$ ). As depicted in Table 1 , the relative enzyme inhibition potential of 2-AFAs was in the order of 2-ODA > 2-HDA > 2-TDA. In addition, it is evident that 2-TDA, with the shortest alkyl chain, was less competitive with regards to inhibiting these enzymes. As reported before, ${ }^{5} \mathrm{PA}$ was inactive against all three enzymes tested $\left(\mathrm{IC}_{50}>100 \mu \mathrm{g} / \mathrm{ml}\right.$ ). Therefore, the presence of a triple bond at $\mathrm{C}-2$, coupled to the right alkyl chain length (longer) seem to be essential for the inhibition of both LS parasites and target enzyme activity.

On the basis of the information obtained from the enzymatic assays, molecular modeling studies were performed as a crucial step towards understanding the mode of the preferential interaction of 2-ODA over 2-TDA and 2-HDA with these enzymes. To achieve this 2-ODA, 2-TDA, and 2-HDA were docked into the active site of both PfFabZ and PfFabG, (Figs. 3 and 4, respectively). The 3D structures of the fatty acid inhibitors were constructed using standard geometric parameters of the molecular modeling software package SYBYL 8.0. Each single optimized conformation of each molecule in the data set was energetically minimized employing the Tripos force field ${ }^{13}$ and the Powell conjugate gradient algorithm $^{14}$ with a convergence criterion of $0.05 \mathrm{kcal} / \mathrm{mol} \AA$ and Gasteiger-Hückel charges. ${ }^{15}$ Molecular docking and scoring protocols were carried out with GOLD 4.1 (Cambridge Crystallographic Data Centre, Cambridge, UK). ${ }^{16}$ Default parameters were used to investigate the possible binding conformations of the ligands within the PfFabG and PfFabZ binding pockets. The X-ray crystallographic data for PfFabG determined at $1.5 \AA$ (PDB ID $2 \mathrm{C} 07)^{17}$ and PfFabZ determined at $2.09 \AA$ (PDB ID 1Z6B) ${ }^{18}$ used in the docking simulations were retrieved from the Protein Data Bank (PDB). The binding site of PfFabG was defined as all the amino acid residues encompassed within a $20 \AA$ radius sphere centered on the three dimensional coordinates of the side chain CG of Asn147. Similarly, the binding site of PfFabZ was defined as all the amino acid residues encompassed within a $20 \AA$ radius sphere centered on the three dimensional coordinates of the side chain NE2 of His98 (Chain B). The docking procedures were repeated 10 times for each inhibitor. The GOLDScore scoring function and visual inspection were employed to select the representative conformation for each inhibitor.

According to the model, the alkyl tails of the 2-ODA, 2-TDA, and 2-HDA inhibitors adopt similar extended conformations into the PfFabZ binding site (Fig. 3). In these conformations, non-polar interactions play a key role in orientating the inhibitors within the binding cavity. Specifically, the alkyl tails are in favorable orientation to make extensive van der Waals contacts to the side 

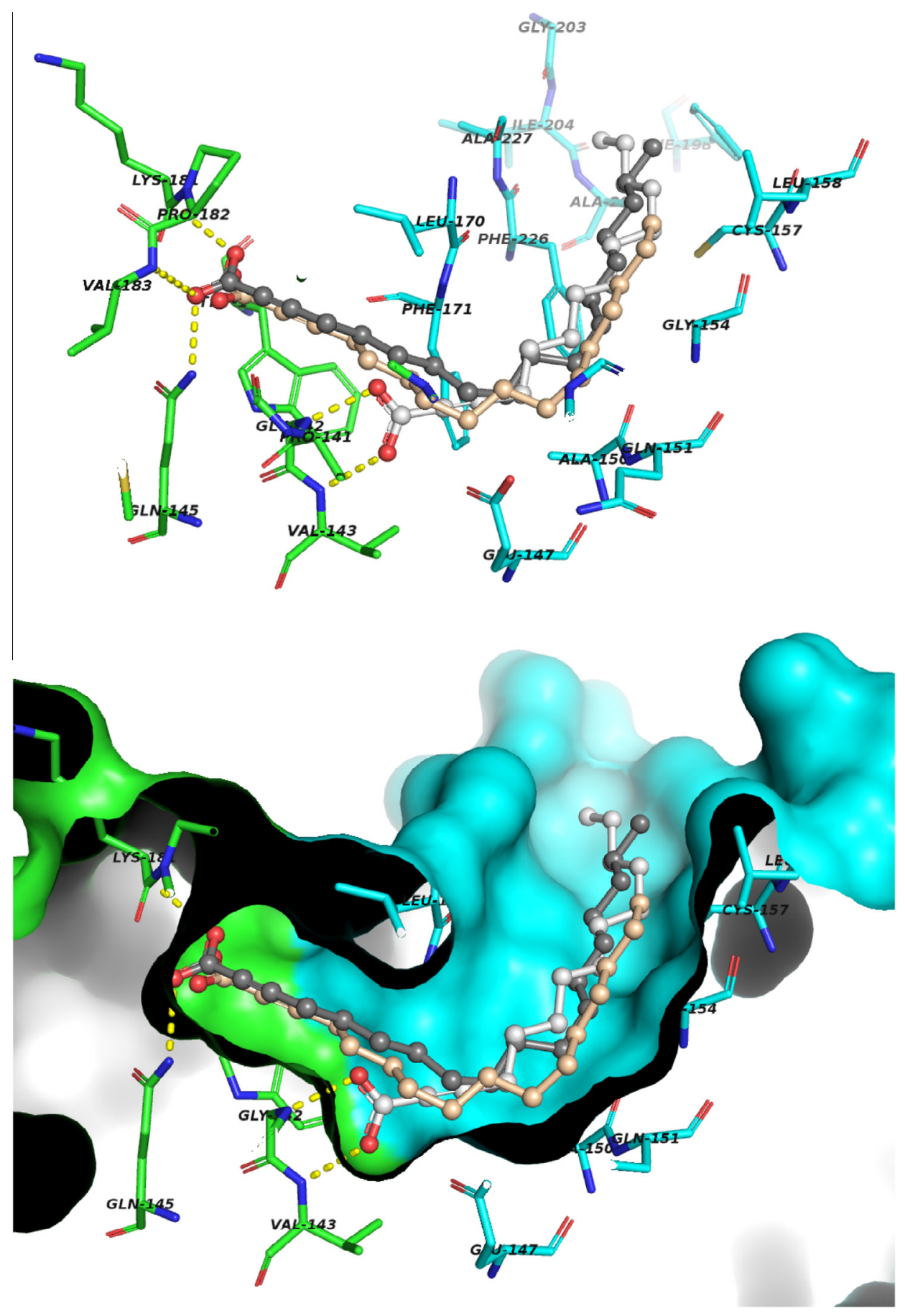

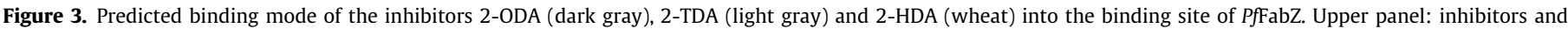

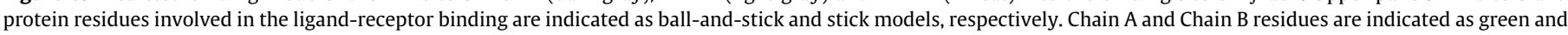

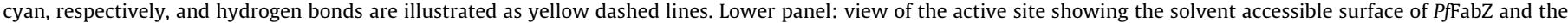
spatial complementarity of the inhibitors.

chain of Ala150, Gly154, Cys157, Leu158, Phe171, Phe198, Ala205, Phe226 and Ala227. In addition, favorable polar interactions assist the stabilization of the inhibitors. However, the hydrophilic heads bind to different regions of the binding site. In the case of 2-TDA, the carboxylic acid substituent accepts two hydrogen bonds from the main chain NHs of Gly142 and Val143. With respect to 2-ODA and 2-HDA, the carboxylic acid substituents are in favorable orientation to accept three hydrogen bonds, one from the side chain $\mathrm{NH}_{2}$ of Gln 145, while the other two from the main chain NHs of Lys181 and Val183. Additionally, the triple bond of
2-ODA and 2-HDA orients the methylene groups towards a hydrophobic cavity formed by the side chains of Leu170, Trp179, Pro182 and Ile189, which favors additional hydrophobic contacts related to the inhibitor 2-TDA. This finding is in good agreement with the enzymatic inhibition data and might explain the differences in the inhibitory activities, that is, 2-ODA $>2$-HDA $>2$-TDA.

The proposed binding modes of 2-ODA, 2-TDA and 2-HDA to PfFabG indicate that the inhibitors occupy a conserved positively charged patch on the surface of the enzyme (Fig. 4). Previous mutagenesis studies on 3-oxoacyl-acyl-carrier (OAR), and a homologue 

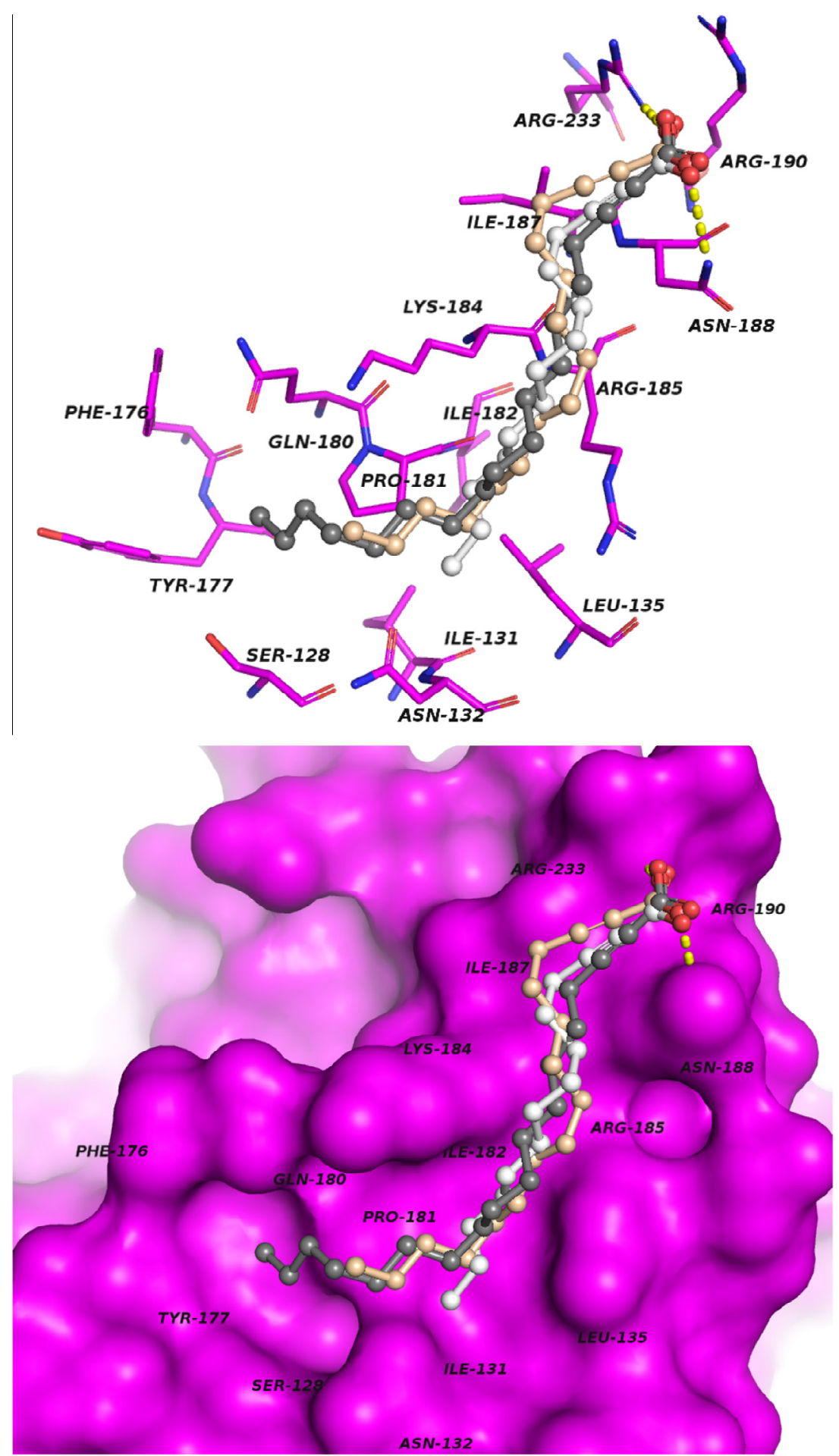

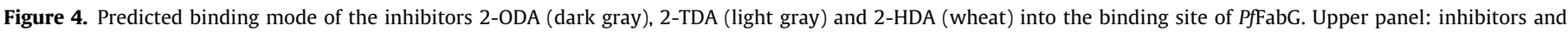

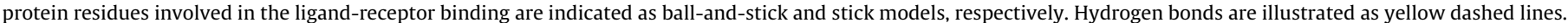
Lower panel: view of the active site showing the solvent accessible surface of PfFabG and the spatial complementarity of the inhibitors.

protein of Escherichia coli, suggested that two arginine residues (e.g., Arg129 and Arg172) play a key role in the binding of a natural substrate. ${ }^{17}$ These residues are conserved in PfFabG (e.g., Arg190 and Arg233) and form part of the positively charged region. According to the model, the negatively charged carboxylic acid substituents of 2-ODA, 2-TDA and 2-HDA are coordinated by ionic interactions with the side chain of the conserved Arg233 residue and accepts a hydrogen bond from the side chain of Asn188 (Fig. 4). Furthermore, extensive van der Waals contacts are made between the alkyl tail of the inhibitors and the side chains of Ile187, Arg185, Arg184, Ile182, Leu135 and Ile131. The enhanced inhibitory activity of 2-ODA related to the other 2-AFAs can be explained by the additional hydrophobic interactions establish by the extra carbon atoms of 2-ODA with a hydrophobic pocket flanked by Pro181, Phe176, Tyr177, Gln180, and Ser128 (Fig. 4).

Next we assessed the in vitro blood stage antiplasmodial activity of 2-ODA and 2-TDA against the multidrug-resistant $P$. falciparum $\mathrm{K} 1$ strain, using the established ${ }^{3} \mathrm{H}$-hypoxanthine 
Table 1

Inhibitory activity of the 2-AFAs and palmitic acid (PA) against PfFAS-II enzymes, liver stage (LS) P. berghei and blood stage (BS) P. falciparum K1 parasites

\begin{tabular}{|c|c|c|c|c|c|c|}
\hline Compound & LS $P$. berghei & PfFabI & PfFabZ & PfFabG & BS $P$. falciparum & L6 cell toxicity* \\
\hline 2-ODA & 0.34 & 0.30 & 0.28 & 0.80 & 6.0 & $5.6^{*}$ \\
\hline 2-TDA & 2.87 & 1.2 & 3.5 & 5.5 & 27.3 & $9.2^{*}$ \\
\hline 2-HDA & 0.48 & $0.38^{* *}$ & $0.58^{* *}$ & $3.5^{* *}$ & $10.4^{* *}$ & $85.9^{* *}$ \\
\hline $\mathrm{PA}$ & $>25$ & $>100^{* *}$ & $>100^{* *}$ & $>100^{* *}$ & $3.8^{* *}$ & $52.7^{* *}$ \\
\hline Standard & $3.4^{\mathrm{a}}$ & $0.015^{\mathrm{b}}$ & $0.03^{c}$ & $0.2^{\mathrm{c}}$ & $0.117^{\mathrm{d}}$ & $0.02^{\mathrm{e}, *}$ \\
\hline
\end{tabular}

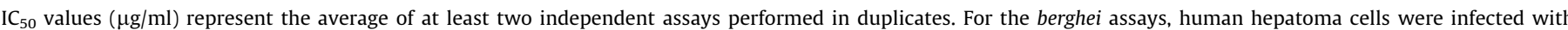

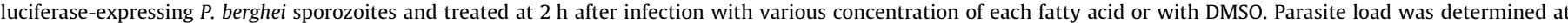

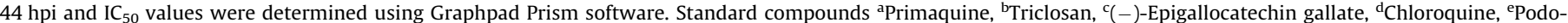
phyllotoxin, Symbols * and ${ }^{* *}$ show data from our previous work ${ }^{2}$ and 3 respectively.

method as described..$^{5}$ As shown in Table 1. and 2-ODA emerged as the most active, hence, the best 2-AFA with dual activity against both Plasmodium species ( IC $_{50}$ 's of 6.0 and $0.34 \mu \mathrm{g} / \mathrm{ml}$, respectively), followed by 2-HDA (IC 50 's of 10.4 and $0.48 \mu \mathrm{g} / \mathrm{ml}$, respectively). As expected, the least effective of the series was 2-TDA with $\mathrm{IC}_{50}$ values of 27.3 and $2.87 \mu \mathrm{g} / \mathrm{ml}$, respectively. Notably, all 2-AFAs exhibited 10-20 times less BS activity. As reported previously, PA was the $C_{16}$ saturated fatty acid with highest BS inhibitory effect $\left(\mathrm{IC}_{50} 3.8 \mu \mathrm{g} / \mathrm{ml}\right)$.

Finally we turned to the assessment of toxic potential of 2-AFAs in comparison to PA. As displayed in Table 1, all four fatty acids bear some general, in vitro toxicity against L6 cells, a primary cell line derived from rat skeletal myoblasts. This followed the order of 2-ODA > 2-TDA > PA > 2-HDA, with 2-ODA being the most toxic. However, the compounds did not exhibit significant toxicity to the human hepatoma Huh7cell line at the highest test concentrations. In order to gain more insights into that aspect, we tested all three 2-AFAs, as well as PA, in zebrafish larvae for the in vivo assessment of general toxicity and hepatotoxicity. Beyond their many genetic, physiological and pharmacological similarities to mammals, ${ }^{19,20}$ zebrafish (Danio rerio) have proven to be an attractive, versatile vertebrate animal model for drug discovery. Embryonic and larval zebrafish can be readily adapted to diverse low- to high-throughput drug-induced toxicity screens, including in vivo assays for geno-, cardio-, neuro- and hepatotoxicity. ${ }^{21-24}$
Following previously described guidelines, ${ }^{25}$ we first evaluated the general toxicity of all four compounds in zebrafish larvae at 3 days post-fertilisation ( $3 \mathrm{dpf}$ ). The maximum-tolerated concentrations (MTCs) were determined during the course of the treatment (3-6 dpf) according to the following parameters: body shape, touch response, pericardial oedema, cardiovascular defects, and death. PA revealed no signs of general toxicity up to the highest concentration tested $(179.2 \mu \mathrm{g} / \mathrm{ml}=700 \mu \mathrm{M})$, however, precipitation in a concentration-dependent manner was observed with this compound. For the 2-AFAs, the MTCs at 6dpf were: $0.20 \mu \mathrm{g} /$ $\mathrm{ml}(=0.8 \mu \mathrm{M})$ for 2 -HDA, $0.27 \mu \mathrm{g} / \mathrm{ml}(=1.2 \mu \mathrm{M})$ for 2-TDA and $0.28 \mu \mathrm{g} / \mathrm{ml}(=1.0 \mu \mathrm{M})$ for 2-ODA.

Next, the hepatotoxic effects of PA, 2-HDA, 2-TDA and 2-ODA were assessed in $3 \mathrm{dpf}$ larvae with a range of concentrations up to their respective MTCs. At $6 \mathrm{dpf}$ ( 3 days post-treatment) the livers were scored according to five phenotypes: normal liver, reduced fluorescence, reduced size, enlarged liver, and absent liver. As shown in Figure 5, when compared to the untreated control (vehicle only, 1\% DMSO) no hepatotoxic effects were induced by PA at the highest concentration tested in our assay $(700 \mu \mathrm{M}=179.2 \mu \mathrm{g} / \mathrm{ml})$. In the same manner, compounds 2-HDA and 2-ODA were also non-hepatotoxic at their MTCs ( 0.8 and $1 \mu \mathrm{M}$, respectively). However, treatment with 2-TDA induced liver toxicity at the MTC $(1.2 \mu \mathrm{M}=0.27 \mu \mathrm{g} / \mathrm{ml})$, which was revealed by livers with slightly reduced size and rounded shape, and with reduced fluorescence.
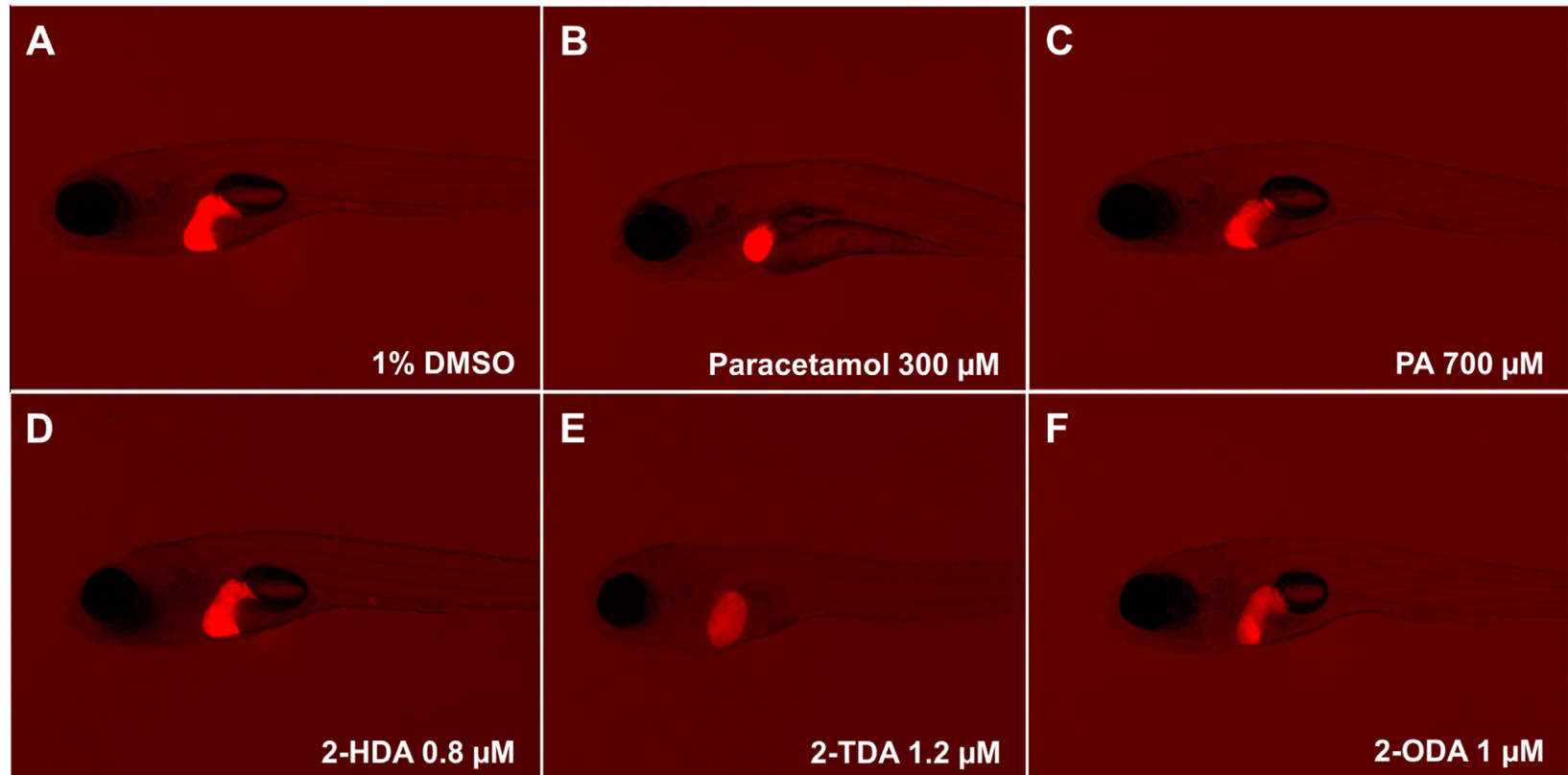

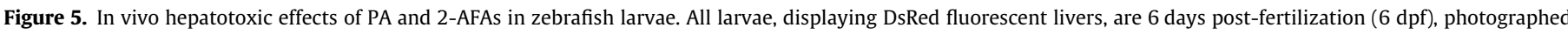

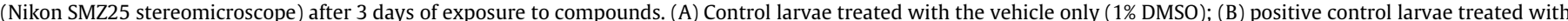

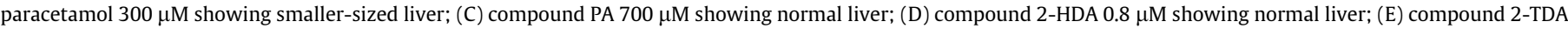
$1.2 \mu \mathrm{M}$ showing round-shaped liver with reduced fluorescence; (F) compound 2-ODA $1 \mu \mathrm{M}$ showing normal liver 
Similar hepatotoxic effects were observed in larvae exposed to paracetamol $(300 \mu \mathrm{M})$, drug used in our assay as a positive control due to its drug-induced liver injury effects. ${ }^{24,26}$ A slightly lower concentration of 2 -TDA $(1.0 \mu \mathrm{M}=0.22 \mu \mathrm{g} / \mathrm{ml})$, however, did not induce any apparent signs of liver toxicity.

Although a limited number of compounds have been evaluated, this study sheds additional light into structural requirements for antiplasmodial activity of 2-AFAs in both life stages of the malaria parasite in the human host, as well as their general toxicity and hepatotoxicity profiles. From the data discussed above, it is obvious that a $C-2$ acetylenic bond and a longer $\left(C_{18}\right)$ alkyl chain are crucial for parasite growth and target enzyme inhibition. In that respect, the potency always followed the trend 2-ODA > 2-HDA > 2-TDA. A similar, but not identical tendency was also observed with in vitro general toxicity towards mammalian primary cells, but not on human hepatic cells. Notably, the 2-AFAs (2-ODA, 2-HDA, 2-TDA) did not exhibit any specific in vivo hepatotoxicity in zebrafish larvae despite testing them at their MTCs (1, $0.8,1.2 \mu \mathrm{M}$, respectively). Nevertheless, we could speculate about the fact that the potential hepatotoxic effects of the 2-AFAs might be masked by general toxicity, induced, in our assay, by relatively low MTCs. Hence, this prompts us to further investigate the compound-induced liver injury properties of 2-AFAs.

Considering the urgent need for the control and eradication of malaria, 2-ODA is worthy of further study as a lead to new antimalarial agents. It exhibits approximately 20 times higher selectivity to hepatic stage malaria parasites over blood stage parasites that may indicate its potential for prophylaxis of malaria. Our future studies will include other analogues with varied alkyl chain length and multiple unsaturation degrees, coupled with more detailed activity/toxicity determination studies.

\section{Acknowledgments}

The project described was supported by Award Number SC1GM084708 from the National Institutes of General Medical Sciences of the NIH and the UPR-Rio Piedras RISE program. We gratefully acknowledge financial support from FAPESP (The State of Sao Paulo Research Foundation, grant \#2013/07600-3) and CNPq (The National Council for Scientific and Technological Development), Brazil. We thank M. Cal and S. Keller-Maerki for parasite assay results. A.G.B. thanks the Commonwealth Scholarship Commission for financial support. M.M.M. has received funding from the European Community's Seventh Framework Programme (FP7/ 2007-2013) under grant agreement $\mathrm{N}^{\circ}$ 242095. M.M.M. is also funded by the European Research Council (Grant ERC-2012StG_20111109) and Fundação para a Ciência e Tecnologia (FCT,
Portugal-Grant EXCL/IMI-MIC/0056/2012). M.A.I. was sponsored by FP7- Marie Curie Actions Initial Training Networks-Interventions Strategies against malaria-InterMal Training fellowship: PITN-GA-2008-215281.

\section{References and notes}

1. Carrara, V. I.; Zwang, J.; Ashley, E. A.; Price, R. N.; Stepniewska, K.; Barends, M.; Brockman, A.; Anderson, T.; McGready, R.; Phaiphun, L.; Proux, S.; van Vugt, M.; Hutagalung, R.; Lwin, K. M.; Phyo, A. P.; Preechapornkul, P.; Imwong, M.; Pukrittayakamee, S.; Singhasivanon, P.; White, N. J.; Nosten, F. PLoS One 2009, 4, e4551.

2. Dondorp, A. M.; Nosten, F.; Yi, P.; Das, D.; Phyo, A. P.; Tarning, J.; Lwin, K. M.; Ariey, F.; Hanpithakpong, W.; Lee, S. J.; Ringwald, P.; Silamut, K.; Imwong, M.; Chotivanich, K.; Lim, P.; Herdman, T.; An, S. S.; Yeung, S.; Singhsivanon, P.; Day, N. P.; Lingegardh, N.; Socheat, D.; White, N. J. N. Engl. J. Med. 2009, 361, 455.

3. Morbidoni, H. R.; Vilchèze, C.; Kremer, L.; Bittman, R.; Sacchettini, J. C.; Jacobs, W. R., Jr. Chem. Biol. 2006, 13, 297.

4. Carballeira, N. M.; Cartagena, M.; Sanabria, D.; Tasdemir, D.; Prada, C. F.; Reguera, R. M.; Balaña-Fouce, R. Bioorg. Med. Chem. Lett. 2012, 22, 6185.

5. Tasdemir, D.; Sanabria, D.; Lauinger, I. L.; Tarun, A.; Herman, R.; Perozzo, R.; Zloh, M.; Kappe, S. H.; Brun, R.; Carballeira, N. M. Bioorg. Med. Chem. 2010, 18, 7475.

6. Sanabria-Ríos, D. J.; Rivera-Torres, Y.; Maldonado-Domínguez, G.; Domínguez, I.; Ríos, C.; Díaz, D.; Rodríguez, J. W.; Altieri-Rivera, J. S.; Ríos-Olivares, E.; Cintrón, G.; Montano, N.; Carballeira, N. M. Chem. Phys. Lipids 2014, 178, 84.

7. Gershon, H.; Shanks, L. Can. J. Microbiol. 1978, 24, 593.

8. Upreti, G. C.; Matocha, M.; Wood, R. Lipids 1981, 16, 315.

9. Carballeira, N. M. Chem. Phys. Lipids 2013, 172-173, 58.

10. Barve, J. A.; Gunstone, F. D. Chem. Phys. Lipids 1971, 7, 311.

11. Spavieri, J.; Allmendinger, A.; Kaiser, M.; Itoe, M. A.; Blunden, G.; Mota, M. M.; Tasdemir, D. Mar. Drugs 2013, 11, 4019.

12. Tasdemir, D.; Lack, G.; Brun, R.; Rüedi, P.; Scapozza, L.; Perozzo, R. J. Med. Chem. 2006, 49, 3345.

13. Clark, M.; Cramer, R. D.; van Opdenbosch, N. J. Comput. Chem. 1989, 10, 982.

14. Powell, M. J. D. Math. Program. 1977, 12, 241.

15. Gasteiger, J.; Marsili, M. Tetrahedron 1980, 36, 3219.

16. Jones, G.; Willett, P.; Glen, R. C.; Leach, A. R.; Taylor, R. D. J. Mol. Biol. 1997, 267, 727.

17. Wickramasinghe, S. R.; Inglis, K. A.; Urch, J. E.; Müller, S.; van Aalten, D. M.; Fairlamb, A. H. Biochem. J. 2006, 393, 447.

18. Kostrewa, D.; Winkler, F. K.; Folkers, G.; Scapozza, L.; Perozzo, R. Protein Sci. 2005, 14, 1570.

19. Zon, L. I.; Peterson, R. T. Nat. Rev. Drug Disc. 2005, 4, 35.

20. Lieschke, G. J.; Currie, P. D. Nat. Rev. Genet. 2007, 8, 353.

21. Chakravarthy, S.; Sadagopan, S.; Nair, A.; Sukumaran, S. K. Zebrafish 2014, 11, 154.

22. Cheng, H.; Kari, G.; Dicker, A. P.; Rodeck, U.; Koch, W. J.; Force, T. Circ. Res. 2011, 109, 1401.

23. Kokel, D.; Bryan, J.; Laggner, C.; White, R.; Cheung, C. Y.; Mateus, R.; Healey, D.; Kim, S.; Werdich, A. A.; Haggarty, S. J.; Macrae, C. A.; Shoichet, B.; Peterson, R. T. Nat. Chem. Biol. 2010, 6, 231.

24. Zhang, X.; Li, C.; Gong, Z. PLoS One 2014, 9, e91874.

25. Lauinger, I. L.; Vivas, L.; Perozzo, R.; Stairiker, C.; Tarun, A.; Zloh, M.; Zhang, X.; Xu, H.; Tonge, P. J.; Franzblau, S. G.; Pham, D.-H.; Esguerra, C. V.; Crawford, A. D.; Maes, L.; Tasdemir, D. J. Nat. Prod. 2013, 1064, 76.

26. McGill, M. R.; Jaeschke, H. Pharm. Res. 2013, 30, 2174. 